Max-Planck-Institut für demografische Forschung

Max Planck Institute for Demographic Research

Doberaner Strasse 114 - D-18057 Rostock - GERMANY

Tel +49 (0) 3812081 - 0; Fax +49 (0) 3812081 - 202;

http://www.demogr.mpg.de

MPIDR WORKING PAPER WP 2002-039

AUGUST 2002

\title{
Demographic Dynamics and \\ Sustainability: \\ Insights from an Integrated, Multi-country Simulation Model
}

Brantley Liddle (btliddle@alum.mit.edu)

This working paper has been approved for release by: Alexia Fürnkranz-Prskawetz

(fuernkranz@demogr.mpg.de), Head of the Research Group on Population, Economy, and Environment.

(C) Copyright is held by the authors.

Working papers of the Max Planck Institute for Demographic Research receive only limited review.

Views or opinions expressed in working papers are attributable to the authors and do not necessarily reflect those of the Institute. 
Demographic Dynamics and Sustainability: Insights from an Integrated, Multi-country

Simulation Model

Brantley Liddle

MPI for Demographic Research

Doberanerstr. 114

18057 Rostock, Germany

btliddle@alum.mit.edu

phone: + 49 (0) 3812081175

fax: $\quad+49(0) 3812081475$

\begin{abstract}
We develop a simulation model to assess sustainable development on three levels: economic (by determining production, consumption, investment, direct foreign investment, technology transfer, and international trade), social (by calculating population change, migration flows, and welfare), and environmental (by computing the difference between pollution and remediation). The model follows "representative" countries that differ in their initial endowments (i.e., natural resource endowment, physical and human capital, technology, and population), and thus in their development levels and prospects. In a world with movement of goods, people, and capital, free substitution in production, flexible economic structures, and the ability to upgrade input factors via investment, we find that, rather than the physical capacity of the earth being responsible for unsustainable paths, the initial disparities in circumstances among countries and the complex of internal and international human interrelationships can lead to a "social non sustainability" or continued divergence of outcomes. In our model history matters (the exogenous history implied by different starting conditions as well as the endogenous history that evolves over the simulations) in the ultimate prospects of countries and how they respond to institutions (e.g., free trade). Many of the most important country-specific starting points relate to population: human capital and population size, structure, and rates of change.
\end{abstract}

\title{
Disclaimer
}

The views expressed in this paper are the author's own views and do not necessarily represent those of the Max Plank Institute for Demographic Research. 


\section{Introduction and Background}

Much of the population debate has been couched in the distinctions made by "population pessimists" and "population optimists." Population pessimists believe that rapid population growth will overwhelm any induced response by technological progress and capital accumulation (Coal and Hoover, 1958 and Ehrlich, 1968). In addition, high youth-dependency, they believe, raises the requirements for consumption at the expense of savings. Following the logic of the familiar "IPAT" identity—where I is environmental impact, $\mathrm{P}$ is population, A is affluence or consumption per capita, and $\mathrm{T}$ is impact per unit of consumption-pessimists argue that more people necessarily result in more human impact on the environment. In general pessimistic models focus on the short to medium run, do not consider feedbacks like substitution in the face of population pressures, and omit possible positive impacts of population like scale economies. Population optimists believe that rapid population growth allows countries to capture economies of scale and promotes technological innovation, either because population pressure or scarcity induces technological progress (Boserup, 1981), or because more people mean more good ideas (Simon, 1981). The optimists focus on the longer run and stress the importance of feedbacks, particularly price induced substitutions.

More recently, a "revisionist position” has emerged. Kelley (2001) defines revisionism not by its conclusions_-revisionists typically argue that most developing countries would benefit from slower population growth—but by its methods, that is highlighting “... the intermediate to longer run, taking into account both direct and indirect impacts, and feedbacks within economic, political, and social systems." This new literature argues that the growth of the working-aged population is good for economic growth while growth of young, dependant population is not. In 
other words, the demographic transition (from high fertility and mortality to low fertility and mortality) will be first a "burden," as the youth cohorts increase, but then a "gift," as the middle, working aged cohorts swell, and lastly, perhaps, a burden again as aging progresses causing the retired cohorts to rise. Revisionists concerned with the environment criticize the IPAT framework for failing to capture interdependencies among $\mathrm{P}, \mathrm{A}$, and $\mathrm{T}$.

Much recent, interdisciplinary research has focused on aspects of the economicpopulation-environment system. Yet, many of these studies focus on only two of the three important subsystems. In addition, studies often consider only one or more developed countries or one or more developing countries, and ignore interactions among levels of development. Lastly, when studies do consider both developed and developing countries, they usually involve cross-sectional analysis, and thus, the studies assume transitions or transformations, rather than directly model or observe them. The simulation modeling technique, in theory, can address the above shortcomings by building complete, multi-country dynamic models and running them over long horizons. In addition, as Simon (1977) argues, simulation allows one "to compare the results of population growth structures [or other variable structures of interest] that have not existed."

Many simulation models, however, suffer from some combination (of more than one) of no environment, not multi-country, no endogenous growth, and no developed-developing country interactions (see reviews by Sanderson, 1980 \& 1992; Dellink, 1999; and Loschel, 2002). Bloom and Canning (2001) argue that models dealing with the "new" demography—emphasizing agestructure effects rather than total population—should necessarily use a systems framework. Yet, their own model, which does not include environment, is currently at only the schematic level. Other population revisionists that use simulation models (e.g., Williamson and Higgins, 2001 and Lee et al., 2001) developed models that are at most partial equilibrium models and are used to 
project variables like the savings rate, rather than to account for feedbacks or interrelationships at multiple levels of a complex, integrated system.

We develop a simulation model, borrowing from economics, demography, and environmental and political science, to simultaneously consider environment, economic development, and population/politics by focusing specifically on the impact of important flows (i.e., pollution, capital, technology, production goods, natural resources, and people). The model can assess sustainable development on three levels: economic (by determining production, consumption, investment, direct foreign investment, foreign aid, technology transfer, and international trade), social (by calculating population growth/change, migration flows, and political stress levels), and environmental (by calculating natural resource use and the difference between environmental pollution and upgrading expenditures). The model follows "representative" countries that differ in their initial endowments (i.e., natural resource endowment, physical and human capital, technology, and population), and thus in their development levels and prospects. We take a revisionist tract by focusing on age structure and transition dynamics. Our model allows us to consider population's impact on per capita consumption as well as the social interdependencies among these variables.

In this paper we focus on the impact of demographic dynamics on sustainability prospects. Specifically, we examine the importance of international migration among countries with different starting points, and review various population policies for aging, rich countries and high population growth, poor ones. The following two sections describe the simulation model: first, a general overview is presented, and the "countries" used in the model are defined; next, the basic modules are described. Some results from the base case are discussed in Section 4, focussing particularly on the source of long-run economic growth in the model. Section 5 
discusses the impact of international migration on rich and middle countries, while section 6 reports the results of population motivated polices in rich and poor countries. Section 7 concludes the paper with a summary of the findings. In addition, an appendix contains some of the important model equations.

\section{Overview of Model}

The model contains the following major segments: (1) a global economic system, covering seven significantly different "countries"; (2) an environmental natural resource system, relating environmental quality and natural resource capacity to welfare and economic production and consumption; and (3) induced changes in population growth and age distribution in each country (including international migration). The economic system comprises sets of relationships in different stages for each country: (1) production of three kinds of commodities (two final goods and one intermediate); (2) patterns of international trade and foreign direct investment; (3) determination of consumption and investment; (4) allocation of investment resources over five investment categories (physical capital, human capital, natural resource capacity, environmental quality upgrading, and development of new technology).

There are four types of decision-makers in the model: (1) all consumers; (2) owners of productive resources, i.e., workers and owners of physical capital and land (or the firms); (3) in each of seven countries, three separate production sectors (thus making 21 individual "firms" overall); and (4) an aggregate national "investor" for each country. The aggregate national investor allocates a country's total investment pool among different types of investment, actually engages all those investment activities, determines the size of the total investment pool via a Keynesian investment function, and determines the market goods-environmental quality tradeoff (by choosing to spend on environmental quality upgrading). 
Each type of decision-maker renders decisions via optimization. Consumers choose their consumption mix (between two final goods) to maximize their utility, derived from demand functions. The national optimal consumption mix is based on national utility maximization reflected in consumer goods demand. Since we have no interest in specific consumption preferences, we assume these demand functions all have unitary price and income elasticities; thus, budgetary allocations to these goods are constant and, for simplicity, are equal for the two goods in all countries. Each "industry firm" maximizes its profits. Since there is no leisure or operation-related depreciation, factor owners maximize period returns to their assets by supplying what is demanded. The national investor maximizes present discounted value of all investments performed in each period, based on the marginal productivity of different investment types and on national preference tradeoffs between market goods and environmental quality. Each type of investment generates a lifetime marginal value productivity, via sectoral production functions and profit-maximizing levels of output, which are transformed into present discounted values via a single social rate of discount specified for each country as a function of its per capita GDP. Relative rates of return form the basis of allocation. The size of the investment pool is given by a Keynesian consumption-investment function, modified by social provision for rates of population dependency.

The model sequentially, deterministically, and in discrete-time runs through (i) equilibria (individual country labor markets and internationally traded goods), (ii) optimizations (profit maximization, final goods consumption mix, and investment mix-including welfaremaximizing goods consumption versus environmental quality choice), and (iii) updates (productive endowments, discount rates, and population-number, age structure, and mortality and fertility rates). Thus, at the end (and as a result) of this sequence of events, each country has 
a new set of input endowments and prices. In addition, there is a new set of international trade prices. In this manner the whole global system will generate 90-100-period (or year) national trajectories $^{1}$.

The country initial conditions are based on judgmental stereotypes of Rich, Middle, and Poor countries, as enhanced by empirical data on country factor endowments; however, only the age structure and birth and death rates are taken directly from the empirical data of specific countries (from Keyfitz and Flieger, 1990). Since the different levels of development or per capita GDP (in our model and empirically) are essentially defined in terms of technology, human capital, and physical capital per capita, differences within each level of development refer to population size and resource (land) endowment. Middle countries differ as well in population growth rates.

So, there are two Rich countries, one with larger total population and higher resource endowment per capita; three Middle countries, varying in population, resource base, and population growth; and two Poor countries, differing in population size. The two Poor countries have the greatest resource endowment, followed by Middle3, then Middle2 and Rich2; Middle1 and Rich1 have the smallest resource endowment. The Rich countries' populations have low birth rates and advanced age structures (based on the European Community circa 1980). The three Middle countries use data from Venezuela in 1975, Chile in 1980, and Taiwan in 1985, and thus, vary in the degree to which they have undergone demographic transition. The Poor

\footnotetext{
${ }^{1}$ To calibrate and test the limits of the entire model a series of nested, two-level, full and fractional factorial
} experimental designs were used. Factorial designs (described in detail in Schmidt and Launsby, 1992) allow study of the effects of changes in levels of independent factors as well as of interaction effects. In general, our model's behavior is not sensitive even to reasonably large changes in parameters - there is numerical sensitivity to changes in some parameters; however, behavior robustness is most important for our findings. 
countries have high birth rates and young age structures (initial data from Guatemala in 1985).

Table 1 shows the most important initial country endowments (these data-with the exception of TFRs and dependency ratios_-as well as the simulation output, are "stylized" and in generic units applicable to the specific variables they describe, e.g., units of physical capital, production, consumption, etc.).

\section{Place Table 1 here}

\section{Model Modules}

\subsection{Production module}

In each country, there are three production sectors: resource intensive industry (producing a final good), resource nonintensive ("service”) industry (producing a final good), and natural resource extraction industry (producing an intermediate good). Final goods and processed natural resources are tradables, so their prices are the same for all countries; wage and rent rates are determined locally. Because labor (but not capital) is completely mobile (within each country), countries can shift production each period for competitive advantage. Since the producers are treated as profit-maximizing price takers, and since physical capital is not sectorally mobile, the amount of each good produced by each country is a straight-forward optimization calculation. The local wage rate for each country clears the labor market each period. At the end of each period each country's rent rate on physical capital is updated by recalculating the average marginal value product of capital for the three sectors, weighted by the total amount of capital in each sector. Lastly, world prices for the two final consumption goods and the intermediate, natural resource good are calculated for use in the following period. These prices are calculated iteratively by equating forecasted world supply and demand. This (arguably simplified) solution method results in actual global supplies and demands that equate within $+/$ - one percent (after an 
initialization process taking from three to seven periods). The national aggregate adjustments in equilibrium have many lags, constraints, and uncertainties, making for varied speeds of adjustment. These adjustments are too complex to model simultaneously, so we simplify by adjusting prices at the end of each period, and leaving the direction of behavioral adjustments to these new prices to the next period. Adjustments, therefore, lead to continued temporal changes-a main focus in the model.

The production functions for the two final consumer goods sectors are of "Barro" form. The production function for the resource extraction sector is slightly different in that we include a drag parameter to allow for heavy recent production to increase rapidly the cost of further extraction. This increasing cost to extract can lead to increasing prices for the natural resource, despite its inexhaustibility. All the production functions are assumed to have constant returns to scale. The resource intensive industry is less labor intensive than the resource nonintensive one. The equations as well as the exponents used (see Table A-1) are shown in the appendix.

\subsection{Investment module}

The share of a country's total GDP allocated for investment depends positively on the country's per capita GDP relative to the initial per capita GDP of the richest country (a measure of a minimum consumption necessity), and negatively on the country's young (ages 0-14) and aged (65+) dependency (i.e., the ratio of those cohorts to the total population). This relationship is one of the most important in the $\operatorname{model}^{2}$ :

$c=0.34+-0.071 \ln \left(G D P / G D P_{0}^{R}\right)+0.7 \times p o p(0-14)+2.1 \times p o p(65+)$

\footnotetext{
${ }^{2}$ The one exception to the model's lack of behavioral sensitivity occurs when the coefficients in Equation 1 are adjusted (by one standard deviation from their econometrically derived values) in the way that constrains investment the most. Under this scenario the rich countries' per capita GDP displays "growth and then collapse," as their share of income for investment eventually reaches zero (driven by their population aging).
} 
where $c$ is the fraction of GDP for consumption, GDP is per capita GDP, $G D P_{0}{ }^{R}$ is the initial per capita GDP of the Rich country, pop $(0-14)$ is the fraction of population aged $0-14$, and pop(65+) is the fraction of population over 65. The GDP ratio term as well as $c$ are constrained (by other equations) to be less than or equal to one. (Because our model does not have a financial sector, countries must invest all income that is not spent on goods consumption in projects commencing in the current period; thus, Equation 1 does not have a term for the return on investment.)

The coefficients in Equation 1 were derived econometrically from panel data (observations in 1985 and 1990) from World Bank (1994). All of the coefficients are statistically significant at least at the five percent level (the adjusted R-squared for the regression was 0.42). We normalize the per capita GDP term (1) to render its impact indifferent to the magnitude of GDP and, thus, appropriate for the stylized values used in the simulation model, and (2) to lessen some of the regression problems common when the dependent variables are a combination of rates and levels. These results are similar to other econometric models, like Kelley and Schmidt (1994) and Mason (1987 \& 1988); however, we attribute a greater drag on investment to aged dependency (perhaps because those analyses were only concerned with developing countries). Our formulation gives Middle countries (with per capita GDPs about one-fourth of Rich countries') an opportunity to invest, but gives Poor countries (with per capita GDPs $1 / 20$ or less of Rich countries') very little chance to catch up.

Each type of investment has a distinctive production function and cost function. From these functions, rates of return are calculated for each investment type. (To project these production and cost functions over the life of an investment, current prices and factor endowments are assumed to be constant.) These different return rates determine the percentages 
of the total investment pool that are allocated to each investment type via a logit share equation (thus, investment funds are allocated in proportion to their relative returns).

Each production sector has its own (well-mixed) physical capital allotment, which is increased through investment and decreased by depreciation (set at five percent a year). Physical capital created (by investment) at the end of one period is considered operational (included in the production function) in the following period. The rate of return on physical capital for each sector depends on the marginal value product of capital for that sector.

Technology enters the production functions as a constant multiplier ( $T$ in Equations 2, 3, and 4 shown in the appendix). There is a ten period lag on technology investment, i.e., the technology multiplier is increased based on technology investment ten periods ago, but the technology multiplier does not depreciate if investment ceases. The increase in the technology multiplier is a logarithmic function of the five-year average of technology investment (ten periods ago). The five-year moving average reflects the fact that innovation is an interactive process that takes time to bear fruit, i.e., labs must "ramp up".

A country's human capital multiple, $H$ (in Equations 2, 3, and 4), is based on the average per student spending on education for the work force. The new $H$ for a country is the weighted (by population size) average of the $H$ of the graduating class and the current $H$ of the workforce. The $H$ of the graduating class is based on the average per student spending (i.e., per student human capital investment) for the class over their 12 periods in school. Hence, for human capital investment both time lags and age structure are important. A one period increase in per student spending likely will have a marginal effect on the graduating class' $H$ since it will be averaged together with the per student spending for the previous 11 periods. Also, a graduating class's $H$ has a greater impact on the country's $H$ as a whole when the graduating class is large relative to 
the work force. In addition, the "life" of a human capital investment is limited by the life expectancy of the graduating class.

Investment in the resource base increases land endowment, $A$ (in Equation 4). This investment is analogous to exploration, but is limited by original land endowment and the sum of past additions to land endowment (via rapidly diminishing returns); thus, countries with small original land endowments but large amount of investment funds could not end up being the major resource producing country. Finally, there is a five period lag between investment in resource replenishment and increases to land endowment.

\subsubsection{Foreign direct investment}

The three middle countries and two rich countries form a multi-national "investment corporation" that invests in and builds, when profitable, physical capital in the two poor countries. The investment corporation allocates its investment pool (the sum of contributions from the five controlling countries) in six investments (physical capital in the three economic sectors of the two poor countries) according to relative returns. The donor countries decide how much to invest in the pool based on relative returns (compared with their average return on "domestic" investments). The investment corporation has its own wage rate, rent rate, cost to produce physical capital (determined by the same function used by the individual countries), discount rate, human capital, and technology. These factors are a weighted average of the factors for the contributing countries (based on their share of the corporation's investment pool). The corporation receives rent payments (based on the rent rate of capital in the host or poor country) on their capital, which it divides among the members according to their share of the total pool. The individual countries repatriate or reinvest their shares depending on the investmentconsumption rate of their home investments (determined by Equation 1). 
The poor countries pay, out of their own GDP, rent on the foreign capital. They also tax the investment corporation's remittances (at 40 percent, a rate roughly optimal for the poor countries). This tax rate influences the amount of foreign capital, beyond the obvious, by affecting the profitability of direct foreign investment since the corporation knows this rate and incorporates it into its return on investment calculation. There is also a technology transfer from the investment corporation to the poor countries. The rate of this transfer depends on the share of a sector's capital that was foreign produced and the technology's "appropriateness" (based on the ratio of human capital of the poor country to that of the investment corporation).

\subsection{Environmental quality and welfare module}

The environmental module essentially considers air pollution and focuses on local and regional impacts of a flow pollutant. The strategy is to relate emissions to economic activity and, to a lesser extent, economic structure and to allow countries to invest in environmental quality upgrading (or remediation). Pollution results from energy use, which is assumed to be a linear function of production in the resource intensive industry and a log-linear function of per capita final goods consumption. The most important aspect of this relationship is that pollution depends on consumption (which means pollution cannot be avoided completely through economic structural change). The log-linear nature of this relationship could be interpreted as consumption becoming relatively less polluting as countries become richer; however, in the absence of investment in environmental quality upgrading, the relationship between consumption and pollution is unambiguous, i.e., more per capita consumption leads to greater per capita pollution. This model feature captures the (often overlooked) empirical fact that primarily-consumptiondriven pollution is significant in developed countries; for example, in the US, personal transport and energy use in the residential building sector account for the majority of total energy 
consumption and a large percentage of air pollution emissions. In addition, personal transport and personal living space have generally increased, not decreased, with wealth in developed countries.

Environmental quality and per capita final goods consumption are the main arguments of the log-linear welfare function. Environmental quality is the difference between the environment in a pure state and "effective pollution," or the amount of pollution produced that is not remediated through investments in environmental quality upgrading. The exponents for goods consumption and environmental quality sum to one, and change so that the welfare weight of environmental quality increases with per capita GDP (equations shown in appendix).

Investment in environmental quality upgrading (remediation) is not really an investment — it is made on a yearly basis—but another form of "consumption". Thus, to calculate its return the extra welfare from a cleaner environment must be converted into consumption terms. First, given no environmental upgrading, the welfare level corresponding to the current consumption and environmental quality is calculated. Next, given a certain expenditure on environmental upgrading and the same consumption level, a higher welfare level is calculated. The benefit of environmental upgrading is measured as the additional goods consumption needed to raise the no-environmental upgrading-welfare level to the environmental upgrading-welfare level. Unlike the other investments, environmental quality upgrading has a one-time immediate payoff, so no discounting is required.

\subsection{Population module}

The mortality rates for infants (0-1), children (1-5), and the aged (approximately 60 and up) are updated every five periods according to changes in per capita GDP (negatively) and time (negatively). Fertility is adjusted at five year intervals according to infant mortality (positively 
affected) and human capital (negatively affected). Aging is performed based on one year cohorts, i.e., instead of one-fifth of a cohort moving to the next one, the amount of people at each age is known. The school age population consists of 6-17, and the working population consists of 1864. Although gender differences are not explicitly modeled, we assume half of each cohort is female to calculate births.

\subsubsection{International migration}

Migrants are assumed to come only from the 20-35-age cohort. The motivation for a worker's migrating is to maximize his human capital adjusted wage. The human capital adjusted wage is the country's wage rate divided by its human capital multiple. This operation reflects the fact that lower skilled immigrants expect lower wages than the higher skilled indigenous population. Besides the obvious impacts of a larger and younger population, migrants affect their host countries in more subtle ways. Migrants bring with them their country's human capital multiple and fertility rates, thus affecting the host country's (through a simple weighted average).

The direction of migration is from countries with a lower human capital adjusted wage to countries with higher ones. Migrants do not return to their source countries nor do they remit any of their wages to relatives in those countries. The destination country of the migrants is determined from a logit model. Besides the relative weighted wage, migrants are attracted to countries where there is a history of past migration from their country and their cultures are similar (as measured by a ratio of the countries' respective human capital). Migrants are discouraged from a particular host country if that country makes an effort to restrict their migration. Countries restrict migration when their population density is high (as measured by the population divided by the initial natural resource endowment) and the prospective migrants' 
culture is very different from their own. Migration is encouraged when a host country's retired population is large relative to its total population.

There are two "judgmental" parameters in this module that are particularly important because they help govern the total flow of people in and out of the countries. One of these parameters is the maximum percent of people migrating each period (set at 0.15 ), i.e., given a very large difference in adjusted wages, the maximum percent of the 20-35-age cohort a country (or our model) will "allow" to leave. The other important parameter is the percent of migrants remaining in the system (set at 0.25 ). Because of the limited number of destination countries in our model (relative to the real world), we believed that all migrants could not be accounted for without rather extreme changes in population occurring. Thus, we allowed the model to be open in this one respect: only a certain percentage of migrants actually will find their way to one of the other six countries; others will simply be "lost".

\section{Base Case and Sources of Growth}

The basic model is one of investment and growth; hence, the two main drags on growth are the two main drags on investment. One drag is population aging, which reduces the percentage of GDP allotted for investment. The other drag is the environment: as countries get richer their assessment of the value of a clean environment (seen through the weight of environmental quality in the welfare function) increases; yet, getting richer means creating more pollution (again through industrial production and, especially, consumption). Countries remedy this conflict by spending on environmental quality upgrading; the consequence of this spending is less money left over for GDP growth producing investments, thus the environmental drag on GDP growth. 
Both of these drags can be seen in the following plot of welfare (Figure 1). In the rich countries, both GDP per capita (not shown) and welfare (defined in Equation 7 in appendix) leveled off in the middle periods, but then rose again. Population aging and the resulting shrinkage of the investment pool, as well as an increased concentration of spending on the environment, caused the leveling off. Migration from the middle and poor countries helped to decrease the dependency ratios, and thus raise investment—-this, along with lower pollution levels because of a shift to less industry production, led to the second increase.

\section{Insert Figure 1}

The constraint on growth is a drag on investment, specifically spending on environmental quality upgrading and population aging. However, investment in and of itself does not guarantee growth; rather, it is a very specific kind of investment that generates sustained growth, that is, technology investment and, to a lessor degree, human capital investment. Even with the environment and population aging drags removed, and considering we have already disallowed the possibility of resource exhaustion to constrain growth, the key to growth is technological advance, not factor accumulation. The following run removes the environment and population dynamics (including migration)—so the share of GDP going toward investment stays essentially constant (and in the rich and middle countries fairly high) —as well as foreign direct investment and technology and human capital improvements. The remaining investments, therefore, are physical capital in the three production sectors and resource base augmentation. In this run per capita GDP (we do not show welfare since the run did not consider pollution) initially grew, but then clearly was limited (see Figure 2), despite the fact that the investment pools grew and the labor forces did not decline. Indeed, as economic theory would suggest, in some periods no 
investment was made because further investment in the physical capital stock would have negative returns.

\section{Insert Figure 2}

Human capital is believed to be and is often defined (i.e., knowledge and skills) like technology does. In addition, human capital enters our production functions in a similar way as technology. To test whether human capital can drive growth in the absence of explicit technology improvements, we reintroduce human capital investment and population dynamics (although there is still no migration). Under these conditions the rich countries reached higher levels of per capita GDP than shown in Figure 2, but their GDP still fell in the later periods. The rapidly aging Middle3 reached levels of per capita GDP that were only slightly higher than in Figure 2, and, like the rich countries, ultimately experienced a fall in GDP. In the aging countries (the rich countries and Middle3), the increase in human capital could not sustain growth because it had to offset the decline in the labor force, and their aging populations led their investment pools to fall toward zero. The poor countries experienced no growth—in fact they had a slight decline in per capita GDP, as well as human capital. This last result suggests that when investment is constrained, the high population growth in these countries is detrimental to per capita GDP growth. Both Middle1 and Middle2 reached higher levels of per capita GDP, and these levels are growing; however, they too will eventually experience GDP decline when their populations ultimately level and then fall. Thus, although in principle both human capital and technological improvements are the sources of sustained economic growth, as long as human capital is tied to population dynamics, its contribution to sustained economic growth will be constrained by the same limits imposed by population. 


\section{Impact of Migration Flows on Countries with Different Starting Points}

In this section we discuss the impact of migration on the rich countries, who are destination countries, and the middle countries, who are both destination and source countries. Out-migration's impact on the poor countries will be discussed in the following section on "population reduction" strategies for those countries.

\section{1 (In-)Migration and rich countries}

As destination countries only, migration provides a clear, substantial benefit to the rich countries whose indigenous populations are aging rapidly. Migration increases the work force directly and lowers aged dependency burdens both directly (the migrants themselves are between 20-35) and indirectly, since migrants tend to come from countries with higher fertility rates. Although the migrants also come from countries with lower human capital, the rich countries do not suffer much human capital dilution since the rich countries can continue to increase their indigenous human capital through the increased investment pool the larger, younger population affords them. In addition, the rich countries also receive migrants from the growing, middle countries who too have high human capital. Without migration, aged dependency burdens reach 0.4 by the $80^{\text {th }}$ period, and the share of GDP going toward investment drops to (or very near) zero. With migration, aged dependency burdens fluctuate between 0.3 and 0.25 , and the share of GDP for investment fluctuates between 10 and 15 percent. As a result of these higher numbers, the total investment pool actually increases in the later periods (after a decline in the middle periods).

Migration is a particularly important benefit to the rich countries when the environment is considered. Welfare levels were only slightly lower under migration during the first 50 periods of the run; in the later periods, after a brief plateau, welfare continued to rise under migration, 
whereas without migration welfare fell. This divergence in the last half of the run resulted in final welfare levels that were around three times higher with migration than without. This model result shows the shortcoming of the linear IPAT framework, which predicts more population results in greater environmental impact. However, in our model, a larger, younger population in the rich countries — who highly value environmental quality_led to a larger investment pool, and that pool was applied toward environmental quality upgrading to such an extent that the increased impact from the larger population was easily compensated for. In other words, the IPAT framework missed a feedback from the "P" to the "T," which ultimately resulted in a lower "I".

Figure 3 shows, for one of the rich countries, the traces of both welfare and the savings rate in runs with and without migration. Again, the savings rate in the run with migration does not fall as much since migrants mitigate aging, and the welfare level rises in the run with migration because the higher savings rate translates into a larger investment pool and more spending on environmental quality upgrading.

\section{Insert Figure 3}

\subsection{Migration and middle countries}

Not surprisingly, migration affects the middle countries differently from either the rich or poor ones. Because the middle countries are both source and destination countries for migrants, migration means for the middle countries, in part, trading their populations for the poor countries' (with those countries' lower human capital and higher fertility rates). In addition, the middle countries have significantly different indigenous population dynamics (different both among themselves and from the other two country "types" or development levels). For each of the three middle countries a series of migration policies, combining both in- and out- migration rules, were run. The three different in- and out- migration rules are: (i) the base case (or normal), (ii) none 
allowed, and (iii) restricted. For in-migration, the restricted rule means only migrants from the other middle countries are allowed (i.e., no in-migration from the poor countries). For outmigration, restricted simply refers to a lower maximum migration rate for the target population (0.06 instead of 0.15 in the base case). The possible combinations of rules results in nine different overall migration polices.

\subsubsection{Middle1}

Middle1 has the youngest and fastest growing population among the middle countries. In addition, because it is most similar to the poor countries, in terms of human capital and fertility, under the base case conditions it received significant in-migration from those countries. In any run where out-migration is limited (the "none" or "restricted" rule was used), but in-migration was not, Middle1 experienced high population growth and finished with a substantially greater population than under any other policy scenario. Under the policy of "normal" (out-migration)"normal" (in-migration), Middle1 was very much trading part of the poor countries' populations for part of its own. Thus, it is not surprising that the worst in- and out- migration rules clearly were the "normal" ones. Because Middle1 typically achieved the lowest per capita income of the middle countries, there was little difference in population between the "none" and "restricted" inmigration rules. The "none" out-migration rule produced a slightly higher per capita GDP than the "restricted" rule throughout the run. The "none-none" (and equivalently the "none-restricted") policy led to a larger population and higher percent of GDP for investment than the "restrictednone" (and "restricted-restricted") policy. However, the difference in per capita GDP between the "none" out-migration policy and the "restricted" one was not great. Assuming that eliminating migration is considerably more costly than controlling it, the best policy for Middle1 is probably "restricted-restricted." 


\subsubsection{Middle2}

Of the five different population profiles used in the model, Middle 2 enjoyed the most modest degree of population growth (i.e., change in total population) and population aging (i.e., change in aged dependency ratio). Thus, out-migration provided little "population relief" for Middle2, and not surprisingly, similar to Middle1 the "normal" rule was clearly the worst and the "none" rule the best. For the first 80 periods the "none" and "restricted" in-migration rules were very close and clearly better than "normal." However, in the last 10 periods, Middle2 began to have some negative impact from aging, and the "restricted" and "normal" rules became (close to each other and) better than the "none" rule. Thus, the best migration policy is "none-restricted". Over the short-run (the first 50 periods or so), the second best policy is "none-none," while over the longer-run (because of some population aging) "restricted-restricted" becomes the second best.

\subsubsection{Middle3}

Middle3 has population dynamics that allow for a very high percentage of GDP for investment early on, but its population aged rapidly, causing a drop in investment even more extreme than experienced by the rich countries. As a result of its unique population dynamics, Middle3 had the most complex pattern of per capita GDP traces in response to the different migration policies. In general, policies that limited both out- and in- migration ("none-none," "none-restricted," "restricted-none," and "restricted-restricted") were the best policies over the middle periods - periods 30-60. Yet, policies that allowed for significant out- or in- migration (“normal-normal," "normal-none," "normal-restricted," and "restricted-normal”) were clearly the worst over this period. Middle3 enjoyed income growth during the middle periods; however, it was still "poorer" than the rich countries, and thus, experienced some out-migration, with this 
loss of its workers hurting the country. At the same time, an influx from the poor countries and from the slower growing and, by now, lower human capital Middle1 put a drag on per capita growth. Because of the high degree of population aging of the indigenous population, policies that limited in-migration ("normal-none," "normal-restricted," "restricted-none," and "nonenone") all led to flat per capita GDP during the last 30 periods.

Policies that allow for in-migration ("none-normal," "restricted-normal," "nonerestricted," "restricted-restricted," and "normal-normal") enjoyed sustained per capita GDP growth in the later periods. Among this second group—-the "sustained-growth" polices—-there was little difference in results over the last 30 periods between the "none" and "restrictive" outmigration rules (i.e., "none-normal" was very similar to "restricted-normal" and "none-restricted" was similar to "restricted-restricted"). This lack of sensitivity to the out-migration rule is not surprising since in situations of income growth people are less likely to want to migrate.

Because the "normal" in-migration rule is clearly the best in the long-run, but the "restricted" rule is much better than "normal" in the short-to-medium-run, choosing an optimal migration policy is difficult for Middle3. Among the policies that allowed for sustained per capita GDP growth, "none-restricted" was the best policy during the first 60 periods, while "nonenormal" was the best over the last 30 (although the "restricted" out-migration rule resulted in only slightly lower income when keeping the in-migration rule constant). The choice between these two policies, and equivalently between these two time horizons, could be made using standard discounting. Alternatively, Middle3 could pursue a dynamic migration policy, i.e., a "switch" strategy where the policy changes, for example, from "none-none" to "none-normal." Figure 4 shows Middle3's per capita GDP for a selected group of the above policies. 


\section{Population Adjustment Polices: Migration vs. Fertility}

In this section we discuss the results of two sets of policy experiments that were aimed at overcoming the challenges for poor and rich countries, respectively. For the poor countries the major challenge was affording sufficient investment to achieve growth in the face of rapid population increases. The rich countries challenge involved affording investment—particularly spending on environmental quality upgrading — at the time national savings rates were falling because of the advanced age of their populations. In addition to reporting and analyzing the results of these two experiments, we place our model in the context of important, new work in the population-development debate.

\subsection{Poor Countries' Policy Experiment}

We assume to reduce their populations the poor countries use the following combinations of fertility control and out-migration policies:

1. Fertility control

a. total fertility rate falls from 5.7 to 2.1 in 25 periods (similar to transition in East Asia).

b. total fertility rate falls from 5.7 to 2.0 in 45 periods (a slower transition rate, closer to Latin America).

c. none

2. Migration

a. low level of out-migration (maximum percent of target cohort that may migrate set to $5 \%$ for Poor 1 and $10 \%$ for Poor2).

b. normal level of out-migration (maximum percent migrating set to $10 \%$ for Poor1 and $15 \%$ for Poor2).

c. switch policy: maximum percent migrating set to normal level for first 50 periods, then switched to low level for remainder of run.

The two population control policies operate at much different rates however, once the policies have "run their course," the final total fertility rates are very similar. The two polices both begin at the $10^{\text {th }}$ period. The "faster" policy (modeled after the East Asian demographic experience) achieves replacement level fertility in about 25 periods. At this time the policy is 
switched off, but fertility continues to fall at the same rate as in the other countries that have completed the demographic transition (the total fertility rate falls to 1.8 by the end of the run). In the "slower" policy (modeled after the transition experience most similar to that of Latin American countries) replacement level fertility is achieved around the $55^{\text {th }}$ period, and the total fertility rate ultimately declines to 1.9. By comparison, the final total fertility rate declines to around 3.0 for runs with no population control policy.

The migration policy had a significant impact on the size of the total population and workforce, but a rather negligible impact on per capita GDP or welfare. Different rates of outmigration can lead to very different population sizes (total and workforce) even when the different rates exist only for a limited time. Out-migration lowers population in two ways: first, most obviously, through the loss of the migrants themselves, and second, since we assume the migrants come from fertile cohorts, migrants cause the number of births to fall (even if fertility rates do not). Indeed, runs with the same population control policy but different migration policies (i.e., low vs. switch) finished with significantly different population levels despite having the same fertility rates and the same migration policy after the $50^{\text {th }}$ period. Furthermore, under the conditions of these runs, the difference in births is as significant as the difference in number of migrants in contributing to the difference in population size. The difference in population sizes is essentially constant after the switch time (period 50). Out-migration over the second half of the run was influenced more by the relative performance of the various countries than by the outmigration policy. The runs with the greatest amount of out-migration over the later periods were the runs with the lowest per capita GDP.

At the levels set in these policies, out-migration primarily influences per capita GDP through the relationship between aging (or aged dependency) and investment. Out-migration 
initially raises aged dependency (and thus, lowers investment as a share of GDP), but ultimately leads to less aging and aged dependency (and, thus, higher investment as a share of GDP). Higher migration at the end (second half) of the run means higher aged dependency and, thus, lower investment and GDP over this same time. By contrast, higher migration early in the run means higher aged dependency early, but lower aged dependency later. Hence, the switch migration policy tends to mean less aging and, thus, higher GDP at the end of the run.

For the smaller poor country, in some runs that are otherwise similar, a policy of greater out-migration produces a slightly higher per capita GDP. However, it is abundantly clear, in comparing runs that differ only in their "population reduction" strategies (migration vs. fertility decline), lowering fertility is far better than encouraging out-migration for both poor countries.

Population control has an important impact on per capita measures. In the eight runs with some form of population control, both per capita GDP and welfare were significantly higher than the four runs with no population control. Fewer births directly improve per capita measures in the obvious way by lowering the number of mouths, however, lower fertility has more subtle impact as well. In runs without the austerity policy, population control (or lower fertility rates) led to a higher share of GDP for investment during much of the run, and to higher investment pools as well. The higher share of investment occurs more because of higher per capita consumption (meaning investment is easier to afford) than because of lower youth dependency burdens that accompany lower fertility. In addition, lower population sizes increase the return to human capital investment (and, thus, lead to more of this type of investment). Indeed, the runs with population control all produce substantially higher human capital multipliers. These benefits of lower fertility do not come at the expense of a smaller workforce, however, since for the first 4050 periods, the fertility rate has a negligible impact on the size of the working population (only migration policy has much effect on workforce over this time).

Figure 5 shows the average workforce size for Poor2 (results for Poor1 are qualitatively the same) under six distinct population reduction strategies-runs that differ in the speed of the demographic transition and the out-migration policy. The figure shows that over the first half of 
the run the out-migration policy is most important; however, over the second half of the run population varies greatly based on the speed of the fertility transition.

Insert Figure 5

Even though the two population control policies result in similar final total fertility rates and youth and aged dependency ratios, their different dynamics lead to other important differences. The faster population control policy produces a smaller population, which enjoys higher per capita GDP and welfare for much of the run, and a higher share of GDP for investment (again, primarily because of higher per capita consumption) for the first half of the run. However, with the faster population control, the countries experience significant and rapid aging over the second half of the run, and, thus, endure the same challenges aging brings to the rich countries, i.e., declining investment pools and workforces, and an increasingly higher percentage of investment going toward environmental quality upgrading. With the slower population control, aging is not as great a problem. Indeed, under these conditions, workforces decline much less, the aged dependency ratio increases at a lower rate, the share of GDP for investment is higher for the second half of the run, as is the investment pool for much of this period, and ultimately, per capita GDP and welfare are higher. The investment pool still falls, however, under the slower population control policy, but because of the pool's larger size, per capita GDP and welfare do not fall.

The younger and larger populations from the slower population control policy mean the investment pool peaks much later (approximately 15 periods later) and at a much higher level (1.6 to 2 times) — even though population is only a third larger — than under the faster population control policy. This discrepancy is important because the countries spend an increasingly higher amount of their investment pools on environmental upgrading in the later periods. 
In runs without population control, both total population and the workforce continue to increase. Although, youth dependency is higher, the much lower aged dependency means the share of GDP for investment finishes substantially higher in these runs. Eventually, the investment pools are larger as well, and, unlike in the population control runs, do not decline. However, without population control, per capita measures like GDP and welfare do not catch-up because of the larger population that results when there is no population control, and because of the greater investment that occurs early on when there is population control.

Accomplishing the demographic transition (achieving roughly replacement level fertility rates) is important to and can help spur economic growth. However, contrary to what some have argued, the speed at which that transition occurs does not seem to be nearly as important as achieving the transition itself. Furthermore, in the absence of any measures to combat population aging (like migration or a pro-natal policy), the speed of the demographic transition implies an intergenerational choice — a faster transition means higher per capita GDP in the short to medium run, but a lower per capita GDP in the long run, than a slower transition. Figure 6 shows the average per capita GDPs for Poor2 under the three different "transitions".

\section{Insert Figure 6}

\subsubsection{Model Results in the Context of Recent, "Revisionist" Population-}

\section{Development Research}

Bloom and Williamson (1998), in their examination of the East Asian growth experience, found that, "Coale and Hoover were right," in that high youth dependency—but not necessarily population growth—acts as a poverty trap for countries with high fertility rates. Bloom and Williamson argued that the demographic transition led economic growth in East Asia by increasing the work force (or labor input) and increasing savings and investment—-both the 
supply (by lowering youth dependency) and the demand (through increasing the workforce and thereby lowering physical capital per worker). According to them, “... population dynamics may have been the single most important determinant of growth" (Bloom and Williamson, 1998).

In our model, if there is no FDI for the poor countries, but only a population control policy, the results are very similar to the Coale and Hoover hypothesis as well as Bloom and Williamson's findings. The poor countries immediately experience higher per capita GDPs as well as higher savings rates. The higher savings rates are more a result of this wealth effectneeding a smaller share of income just for subsistence - than the lowering of youth dependency burdens since there is some delay before these burdens begin to fall substantially. Mostly, the fewer number of mouths causes the early increase in per capita GDP as production increases only slightly. However, the greater amount of investment under the run with lower fertility becomes a more important part of the higher income as the investments begin to pay-off. Indeed, both poor countries experience growth in per capita GDP from the beginning of the run, whereas under similar conditions without any population control (i.e., normal fertility conditions), it takes the poor countries 30-35 periods before per capita GDP begins to grow. As for investment demands, the lower student populations do increase the return to human capital investment—an investment important for long-term economic growth - and the increased production (because of more physical capital) eventually increases the return to technology investment. In all, these policy experiments very much confirm the belief that growth of the working-aged population is not at all bad and may be good for economic growth, but growth of the dependent, non-working population is likely bad for economic growth. 


\subsection{Rich Countries’ Policy Experiment}

As discussed previously, the rich countries' aging presents challenges for their sustained growth — both per capita GDP and welfare. Aging means both a declining workforce and, more importantly, fewer resources going toward investment. One solution for this problem already discussed is migration-particularly effective when the migrants come from higher fertility countries. However, a high amount of migration has social and political costs; thus, programs that may increase indigenous fertility have the attention of policy makers in areas of aging, rich populations like Europe. Indeed, a recent report of a commission of government, business, and academic leaders from the OECD countries, published by the Center for Strategic and International Studies (2002), recommends prompt action to address the problem of aging in OECD countries. The commission is particularly concerned with the negative impacts on growth of declining workforces and the crowding effect that pension and health guarantees for the aged have on public spending in areas like infrastructure and education.

To examine some of the differences between migration and pro-natal, fertility increasing strategies in addressing the challenges brought on by aging societies, we make a series of runs with combinations of various increasing fertility regimes with and without migration. In these runs we do not specify what the pro-natal policy is; rather, we simply assume it is effective to a particular level. The first pro-natal strategy, "replacement, fast", causes the total fertility rate (TFR) to increase from 1.62 in period 10 to 2.19 by period 20 . Over the next 25 periods the TFR falls to 2.09 , and remains at this level for the rest of the run. This fertility change is roughly modeled after the Swedish experience of the 1980s, where the total fertility rate rose from 1.61 in 1983 to 2.13 in 1990 (TFR fell thereafter). (See Andersson 1999 for some explanation of the Swedish experience.) In the pro-natal policy, "replacement, slow", it takes 15 years for the TFR 
to rise to 2. Finally, there is a pro-natal "growth" strategy (run only without migration) that causes the TFR to increase from 1.62 in period 10 to 2.37 by period 20, before gradually falling to 2.20 by period 70 , after which it remains constant. Furthermore, these three pro-natal policies can either take effect "early"—-beginning, as described above, at period 10_or "late"beginning at period 20 . The runs with migration use the same migration model previously described. For comparison purposes, we also run a "base case" that assumes no pro-natal policy and no migration.

The qualitative aspects of the experiment's results are the same for both rich countries; thus, for brevity we concentrate on the results for Rich2. In addition, we separate the presentation by initially looking at runs without migration and then runs containing migration, but first we discuss how migration effects population.

Migrants increase the population in two ways: (i) they immediately increase the population themselves; and (ii) their presence leads to more births (since we assume migrants come from the most fertile cohorts). Migrants lead to more births both because they increase the size of the most fertile cohorts and because they often come from countries with higher indigenous fertility rates. In the terms of demographers, migrants both increase the risk of fertility and the population at risk. Indeed, a run with migration but no pro-natal policy results in more births than a run with the most effective pro-natal policy but without migration. Furthermore, this rise in births from migrants has a much greater impact on the resulting increase in population than the number of migrants themselves. For example, in the run with migration but no pro-natal policy, over 100 periods the grand total of migrants was 43 , but the final period population was 260 persons larger than in the run without migration or a pro-natal policy. Thus, migration plus subsequent births can substantially increase the size of a population and reduce its aging without 
necessarily altering tremendously other more indigenous characteristics (e.g., culture or ethnicity). Our simplifying migrant assimilation assumptions (e.g., that migrants immediately induce a change in their new host country's fertility rates via a weighted average of the migrants' home country's rates and the prevailing rates in the destination country's rates) are clearly thatsimplifications. However, given the previous discussion on the ways migrants affect births, our assumptions that migrants come from the high fertility cohorts and come to stay-they do not plan to nor do they ever return to their source country—probably have more to do with migrants' ultimate impact on a country's population in our model. In other words, given the lags involved in human reproduction and the difficulty in government's changing people's desired family size, it is likely the most effective way to increase births is by increasing the population at risk rather than by increasing the rate of exposure-which of course is precisely what migration does.

For the rich countries, population growth impacts the results in fairly predictable ways. A larger population means greater production, and hence pollution, and a larger investment pool. A younger population means a higher percentage of GDP going toward investment. Subtler, per capita influences on factors like human capital are not present. When the rich countries have population growth, they are really never investment constrained (even toward the end of the runs where they are spending heavily on environmental quality upgrading, their investment pools are large enough to have significant growth enhancing investments as well). Thus, even though the total populations vary greatly among the runs, the final period human capital multiplier ranges from only 9.5 to 10.3 .

Without migration, the pro-natal policy is important, both in terms of the timing of the policy's impact and the effectiveness of its impact. From around the $15^{\text {th }}$ period, only the "growth" pro-natal policy led to an increase in the size of the workforce (see Figure 7 (a)). In 
fact, beginning around the mid-point of the run, for the "replacement, slow" policy and "replacement, fast, late" policy (a policy that does not take effect until the $20^{\text {th }}$ period), the workforce declined from its initial size. Sometime after the $40^{\text {th }}$ period all runs with a pro-natal policy had significantly lower aged dependency, and thus, a higher share of GDP for investment, than in the no migration, no pro-natal case. Significant lag effects are apparent by comparing the "growth" policy to "growth, late" and comparing "replacement, fast" to "replacement, fast, late". Also, most runs had a falling investment share for the last 10 periods. The traces for per capita GDP and welfare showed similar and predictable patterns: the "growth" policy run was among the lowest for the first 50 periods, but was clearly the highest for the last 30 . The two lagged policies caught or nearly caught "growth" by the end of the run, but were substantially below it for most of those last 30 periods.

When migration is added to the various pro-natal policies, all runs experience significant growth in workforce (see Figure 7 (b)), and there is less difference among the different runs in general than there was without migration. The run with migration, but without any pro-natal policy had the smallest population and investment pool, the highest aged dependency, and lowest investment share, as well as the lowest per capita GDP and welfare for the last 25 periods. There is particularly little difference between the two sets of lagged runs ("replacement, fast" and "replacement, fast, late" and "replacement, slow" and "replacement, slow, late") in per capita GDP, welfare, investment pool, or pollution. The runs finished with a higher share of GDP going toward investment than the runs without migration, and with migration this share was steady or increasing for all at the end of the run. Figures 7 (a) \& (b) show the size of the workforce under the various polices without migration.

Insert Figures 7 (a) \& (b) 


\subsubsection{Rich Country Experiment Results in the Context of the Current "Aging} Problem" Debate

In adding migration to a pro-natal strategy, migration seems to function as an insurance policy by smoothing outcomes, or in other words, making the timing and the success rate of the pro-natal program less important. In the choice between a migration or pro-natal policy, migration has the advantage of having a much greater track record of success, as policies to increase desired fertility in developed countries have been notoriously disappointing — at least for sustained periods. Furthermore, as long as the goal of the policy is to mitigate the negative effects of aging, and not for population to reach a constant, replacement level, the amount of migrants needed is far from overwhelming. The aforementioned commission on aging in OECD countries recommended making it easier for nonnative residents to achieve citizenship or permanent residency, and noted the positive impact of high human capital immigrants on the US as well as the potential synergistic effects of them on their source countries-as is the case for India (Center for Strategic and International Studies, 2002). In addition, the commission recognized that policies aimed to increase fertility in developed countries have had mixed results at best.

The UN Population Division, in a recent report (UN, 2000), considered migration as a solution to the problem of declining and aging populations of developed countries. Ultimately, the UN, as well as some of the report's critics (Mayerson, 2001 and Bermingham, 2001), came to the conclusion that migration is an inadequate means of countering population aging and decline. The report (and the two critics cited above) rejected the migration option because the large volume of migrants needed to delay aging in the subject countries would create, "serious social and political objections" (UN, 2000). In calculating population projections, the UN report assumed that migrants would immediately experience the average fertility conditions prevailing 
in their destination country. Yet, both the UN and one of its critics (Mayerson) pointed out the fact that this is an unrealistic assumption. However, neither the UN nor Mayerson addressed the logical conclusion that this assumption inflates the number of migrants needed to mitigate aging in the destination countries, and thus, the social stress caused by the migrants - a primary objection both expressed to the policy. Another fault of the UN report is assuming that the goal of such a policy should be "replacement migration" or constant populations, as opposed to simply mitigating extreme degrees of aging and workforce shrinkage. Likewise, the UN critics (at least Mayerson and Bermingham) erred in concluding that population growth is necessarily bad-a conclusion, it appears, driven by a linear interpretation of the IPAT equation, i.e., more population in developed countries means more pollution.

\section{Conclusions}

We have tried to develop a model that is "more complete" than most, i.e., a fuller treatment of population, an economic module that also considers international capital movements, and some consideration for the environment. But the most important aspects of our work in differentiating it from others, is our modeling of a diversity of "country types," and our explicit modeling of human capital and technology investments/improvements-widely accepted as the drivers of sustained economic growth. We have allowed countries to differ in initial human capital and technology levels, and thus, in initial development or wealth levels, as well as in areas, like age structure, in which there is less likelihood of rapid convergence.

This paper focused on the impacts of different demographic dynamics in our stylized rich, middle, and poor countries. We found that modeling feedbacks in the population-economyenvironment system means that conclusions derived from the linear IPAT identity do not necessarily hold. Specifically, migration in the rich countries led to younger, larger populations 
and ultimately lower levels of environmental impact. In addition, we found that migration into the rich countries can mitigate the impact of aging (although, perhaps, not reverse it altogether), and can do so without creating substantial social dislocations since a relatively small number of migrants may be sufficient. For the middle countries, both source and destination countries of migrants, the impact of international migrations was much more complex. For at least one middle country (Middle3), a migration policy needed to be dynamic. Lastly, in the poor countries, as the population revisionists contend, lowering fertility rates did lead to higher per capita growth; but, lowering fertility rates was a far more effective way to spur growth than encouraging outmigration. Yet, the speed at which this transition occurred did not affect the ultimate level or rate of income growth; rather, it suggested an intergenerational tradeoff. In other words, if age structure affects savings and investment, and thus economic growth, then a faster demographic transition (over a slower one) means higher growth in the short to medium run; but because such a transition results in faster aging as well, it can result in lower income in the longer run. 


\section{References}

Andersson, G. 1999. Childbearing trends in Sweden 1961-1997. European Journal of Population: $15(1), 1-24$.

Bermingham, John R. 2001. "Immigration: Not a Solution to Problems of Population Decline and Aging," Population and Environment. Volume 22, Number 4, pp. 355-63.

Bloom, David and David Canning. 2001 "Cumulative Causality, Economic Growth, and the Demographic Transition." in Population Matters: Demographic Change, Economic Growth, and Poverty in the Developing World. Nancy Birdsall, Allen C. Kelley, and Steven W. Sinding editors. Oxford: Oxford University Press. Pp. 165-97.

Bloom, David E. and Jeffrey G. Williamson. 1998. "Demographic Transitions and Economic Miracles in Emerging Asia." The World Bank Economic Review, 12, 3: 419-455.

Boserup, Ester. 1981. Population and Technological Change: A Study of Long-Term Trends. Chicago: University of Chicago Press.

Center for Strategic and International Studies. 2002. "Meeting the Challenge of Global Aging: A Report to World Leaders from the CSIS Commission on Global Aging." CSIS: Washington, DC.

Coale, Ansley J. and Edgar Hoover. 1958. Population Growth and Economic Development in Low-Income Countries. Princeton, NJ: Princeton University Press.

Dellink, R.B. 1999. "Environmental-economic modeling: a survey of pollution, abatement and economic growth." Wageningen University, Wageningen, Netherlands.

Ehrlich, Paul R. 1968. The Population Bomb. New York: Ballantine.

Kelley, Allen C. 2001. "The population debate in historical perspective: revisionism revised," in Population Matters: Demographic Change, Economic Growth, and Poverty in the Developing World. Nancy Birdsall, Allen C. Kelley, and Steven W. Sinding editors. Oxford: Oxford University Press. pp. 24-54.

Kelley, A. C. and Schmidt, R.M.,1994. Population and income change: recent evidence. World Bank Discussion Paper 249, Washington, DC.

Keyfitz, N. \& Flieger, W. (1990). World Population Growth and Aging: Demographic Trends in the Late Twentieth Century. University of Chicago Press, Chicago.

Lee, Ronald D., Andrew Mason, and Tim Miller. 2001. "Saving, Wealth, and Population," in Population Matters: Demographic Change, Economic Growth, and Poverty in the Developing World. Nancy Birdsall, Allen C. Kelley, and Steven W. Sinding editors. Oxford: Oxford University Press. Pp. 137-64 
Loschel, Andreas. 2002. "Technological Change in Economic Models of Environmental Policy: A Survey." Working paper, University of Mannheim, Germany.

Mason, A. (1987). National Saving Rates and Population Growth: A New Model and New Evidence. In Johnson, D. G. \& Lee, R. D. (Eds.), Population Growth and Economic Development: Issues and Evidence, University of Wisconsin Press, Madison (pp. 523-560).

Mason, A. (1988). Saving, Economic Growth and Demographic Change. Population and Development Review, 14 (March), 113-144.

Meyerson, Frederick A.B. 2001. "Replacement Migration: A Questionable Tactic for Delaying the Inevitable Effects of Fertility Transition," Population and Environment. Volume 22, Number 4, pp. 401-9.

OECD. (1995). The OECD Input-Output Database. Organization for Economic Co-operation and Development, Paris.

Sanderson, Warren C. 1980. Economic-Demographic Simulation Models: A Review of Their Usefulness for Policy Analysis. RR-80-14. IIASA. Laxenburg, Austria.

Sanderson, W.C. 1992. Simulation models of economic, demographic, and environmental interactions: are they on a sustainable development path? Working paper WP-92-87, IIASA, Laxenburg, Austria.

Schmidt, S. R. and Launsby, R.G. (1992). Understanding Industrial Designed Experiments, Third Edition. Air Academy Press, Colorado Springs.

Simon, J. L. (1977). The Economics of Population Growth. Princeton University Press, Princeton, NJ.

Simon, Julian. 1981. The Ultimate Resource. Princeton, NJ: Princeton University Press.

United Nations Population Division. 2000. Replacement Migration: Is it a Solution to Declining and Ageing Populations? New York: United Nations.

Williamson, Jeffrey G. and Higgins, Matthew. 2001. "The Accumulation and Demography Connection in East Asia." in Population Change and Economic Development in East Asia. Edited by Andrew Mason, Stanford, CA: Stanford University Press, pp. 123-54.

World Bank, 1994. World Tables 1994. The World Bank, Washington, DC. 


\section{Appendix: Important Model Equations and Production Function Exponents}

The production functions for the two final consumer goods sectors, with all variables and parameters specific to each period t, are:

Resource nonintensive service sector, S:

$\mathrm{Q}_{\mathrm{S}}=\mathrm{T}\left(\mathrm{HL}_{\mathrm{S}}\right)^{\mathrm{bls}} \mathrm{K}_{\mathrm{S}}{ }^{\mathrm{bks}} \mathrm{R}_{\mathrm{S}}{ }^{\mathrm{brs}}$

Resource intensive industry sector, I:

$\mathrm{Q}_{\mathrm{I}}=\mathrm{T}\left(\mathrm{HL}_{\mathrm{I}}\right)^{\mathrm{bli}} \mathrm{K}_{\mathrm{I}}^{\mathrm{bki}} \mathrm{R}_{\mathrm{I}}^{\mathrm{bri}}$

Where:

$\mathrm{Q}_{\mathrm{S}}, \mathrm{Q}_{\mathrm{I}}$ : output for two sectors

$\mathrm{T}$ : input-neutral technological improvements (same for all sectors)

$\mathrm{L}_{\mathrm{x}}, \mathrm{K}_{\mathrm{x}}, \mathrm{R}_{\mathrm{x}}(\mathrm{x}=\mathrm{S}, \mathrm{I})$ : labor, capital, natural resource input for individual sectors

$\mathrm{H}$ : human capital factor (same for all sectors)

bkx, blx, brx $(x=s, i)$ : productivity exponents for three inputs and two sectors

The production function for the resource extraction sector, also specific to each period $\mathrm{t}$, is:

$$
R=A T K_{R}^{\alpha k r}\left(H L_{R}\right)^{\alpha n r} \overline{R^{\beta}}
$$

Where:

$\mathrm{R}$ : amount of extraction

A : country specific factor representing land endowment

$\mathrm{T}$ : input-neutral technological improvements (again, same for all sectors)

$\mathrm{L}_{\mathrm{R}}, \mathrm{K}_{\mathrm{R}}$ : labor and capital input

$\mathrm{H}$ : human capital factor (again, same for all sectors)

$\alpha k r, \alpha n r$ : productivity exponents for capital and labor

$\bar{R}: 8$ year moving average of past extraction 
B : country specific drag parameter based on the extent of recent extraction (less than -1$)$.

The exponents used in Equations 2-4 were estimated from empirical data of factor shares using The OECD Input-Output Database (1995), as applied to the stylized definitions of our aggregate sectors.

\section{Place Table A-1 here}

Environmental Quality Module Equations, again with all variables and parameters specific to each period $\mathrm{t}$, are:

$E Q=E Q_{0}-P$

$$
P=\bar{P}(1-\Pi)
$$

$W=E Q^{\theta} C^{\phi}$

$1=\theta+\phi$

$\theta=k-d g^{G D P}$

$$
\Pi=0.99\left(1-f^{e}\right)
$$

where $E Q$ is environmental quality, $E Q_{0}$ is environmental quality in a pure state (arbitrarily set high enough so $E Q$ is positive), $P$ is effective pollution consumed, $\bar{P}$ is pollution produced, $\Pi$ is the percentage remediated, $W$ is welfare, $C$ is per capita final goods consumption, $G D P$ is per capita GDP, and $k, d$, and $g$ are positives constants (all less than 1.0 and $\mathrm{k}>\mathrm{dg}$ ) that set bounds for the welfare weight on environmental quality. The percentage remediated is based on the amount of investment in environmental quality upgrading per unit of pollution produced, $e$, and the ease of remediation, $f$ (currently set to 0.05 ). Thus, the maximum amount remediated is 99 percent of pollution produced. 
Table 1: Initial Country Endowments

\begin{tabular}{lccccccc}
\hline & $\begin{array}{c}\text { Technology } \\
\text { multiplier }^{1}\end{array}$ & $\begin{array}{c}\text { Human } \\
\text { capital } \\
\text { multiplier }\end{array}$ & $\begin{array}{c}\text { Land } \\
\text { endowment }^{3}\end{array}$ & $\begin{array}{c}\text { Total } \\
\text { population }\end{array}$ & TFR & $\begin{array}{c}\text { Aged } \\
\text { dependency } \\
\text { ratio }\end{array}$ & $\begin{array}{c}\text { Youth } \\
\text { dependency } \\
\text { ratio }\end{array}$ \\
\hline Rich1 & 3.0 & 3.0 & 2.5 & 182 & 1.81 & 0.244 & 0.536 \\
Rich2 & 3.0 & 3.0 & 10.0 & 300 & 1.81 & 0.244 & 0.536 \\
Middle1 & 2.0 & 2.0 & 5.0 & 204 & 3.58 & 0.073 & 1.086 \\
Middle2 & 2.0 & 2.0 & 10.0 & 200 & 2.47 & 0.105 & 0.741 \\
Middle3 & 2.0 & 2.0 & 15.0 & 300 & 1.88 & 0.106 & 0.635 \\
Poor1 & 1.2 & 1.0 & 20.0 & 465 & 5.96 & 0.071 & 1.392 \\
Poor2 & 1.2 & 1.0 & 20.0 & 200 & 5.96 & 0.071 & 1.392 \\
\hline
\end{tabular}

Notes: (1) The $T$ in Equations 2-4. (2) The $H$ in Equations 2-4. (3) The $A$ in Equation 4.

Table A-1: Production Function Exponents

\begin{tabular}{lccc}
\hline & $\begin{array}{c}\text { Extraction/resource } \\
\text { replenishment }\end{array}$ & $\begin{array}{c}\text { Resource } \\
\text { intensive } \\
\text { "industry" }\end{array}$ & $\begin{array}{c}\text { Resource } \\
\text { nonintensive } \\
\text { "service" }\end{array}$ \\
\hline Labor share & 0.3 & 0.45 & 0.6 \\
Capital share & 0.7 & 0.20 & 0.3 \\
Natural resource share & & 0.35 & 0.1 \\
\hline
\end{tabular}




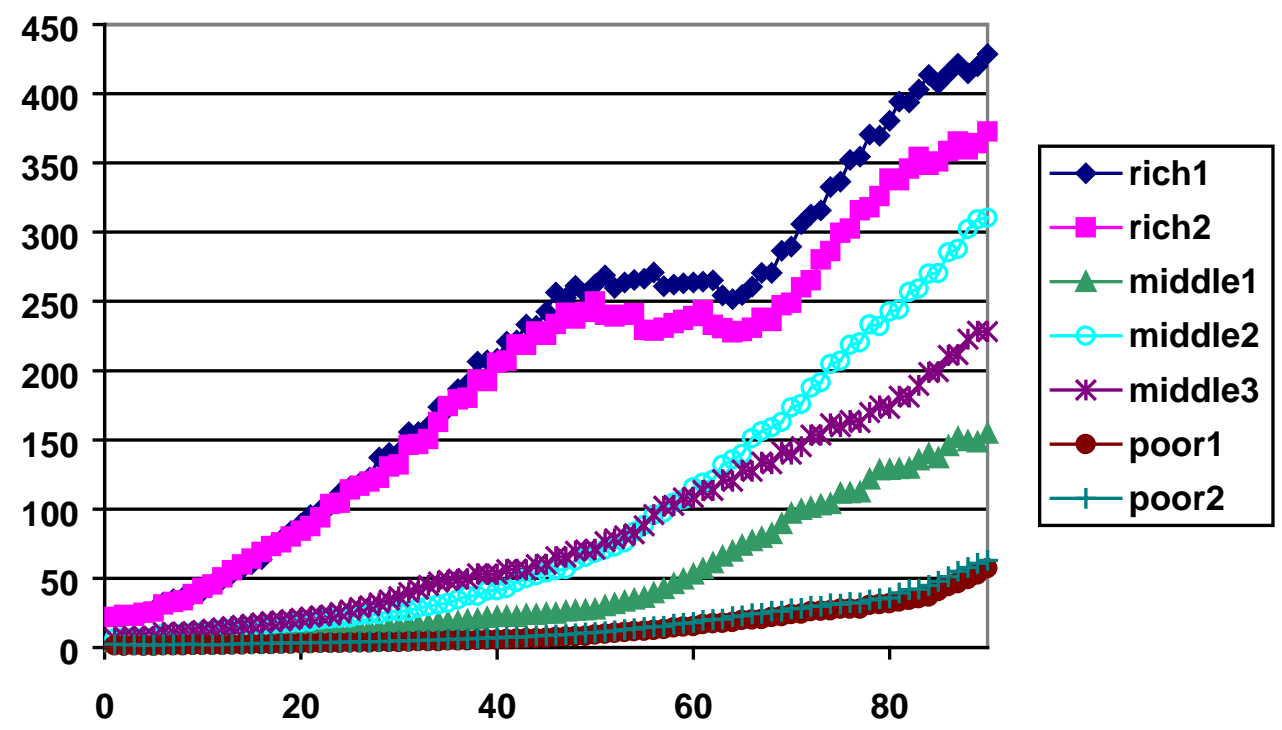

Figure 1: Welfare levels for all countries in the base case run.

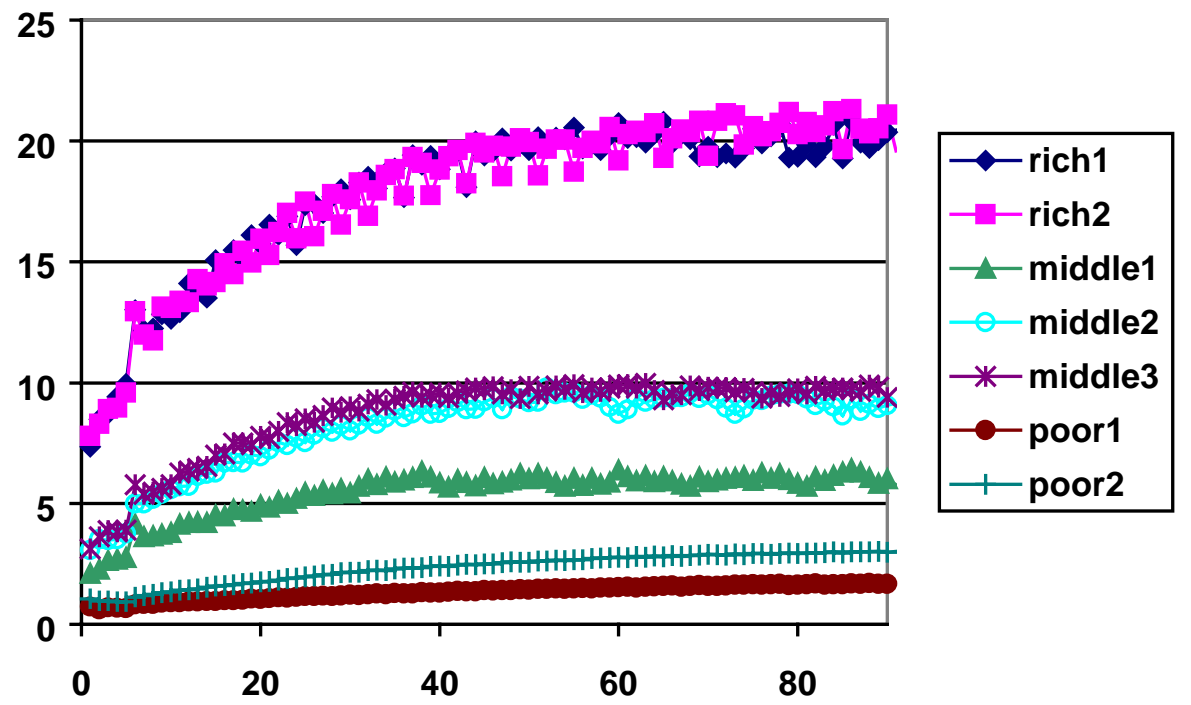

Figure 2: Per capita GDP for all countries when the base case is run without the environmental module (thus, no environmental drag), without population dynamics (thus, no population drag), without FDI, and without the ability to increase technology or human capital via investment (i.e., constant technology and human capital levels). 


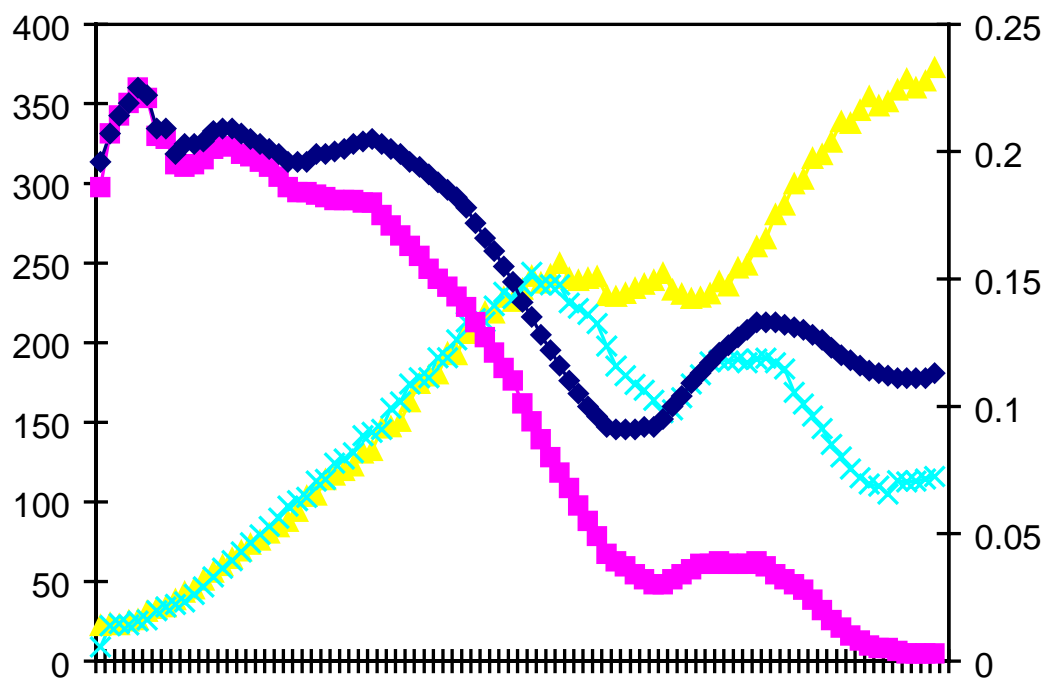

welfare, migration $\quad-x$ welfare, no migration

savings rate no migration $\longrightarrow-$ savings rate migration

Figure 3. The right-hand axis shows, for the larger rich country, the savings rate with and without migration. With migration there was less aging in the rich country; thus, the savings rate did not fall as much-indeed it leveled-over the second half of the run. The left-hand axis shows welfare for the same country. Welfare diverges because the higher savings rate with migration translated into a larger investment pool and more spending on environmental quality upgrading and, thus, higher welfare levels. 


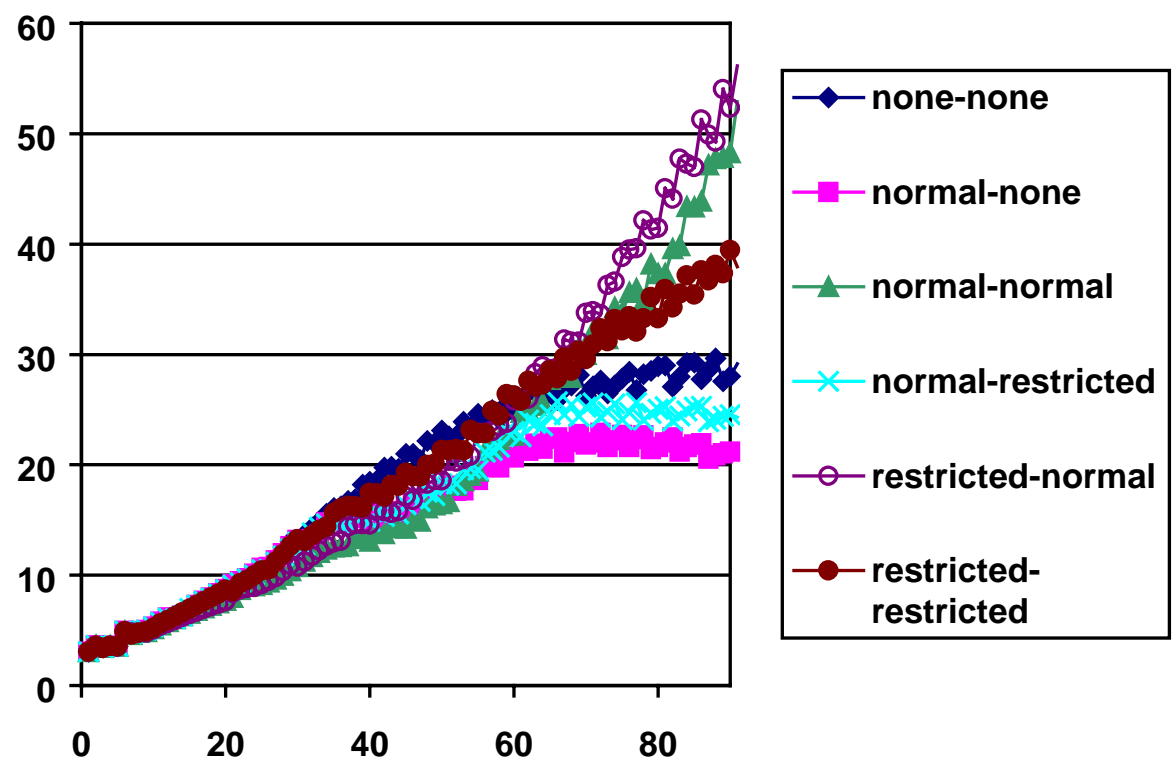

Figure 4: Per capita GDP for Middle3 under selective migration policies. The out-migration rule is designated first followed by the in-migration rule. For example, "none-none" refers to the policy that combines the "none" out-migration rule with the "none" in-migration rule. See the text (Section 5.2) for definitions of the three rules.
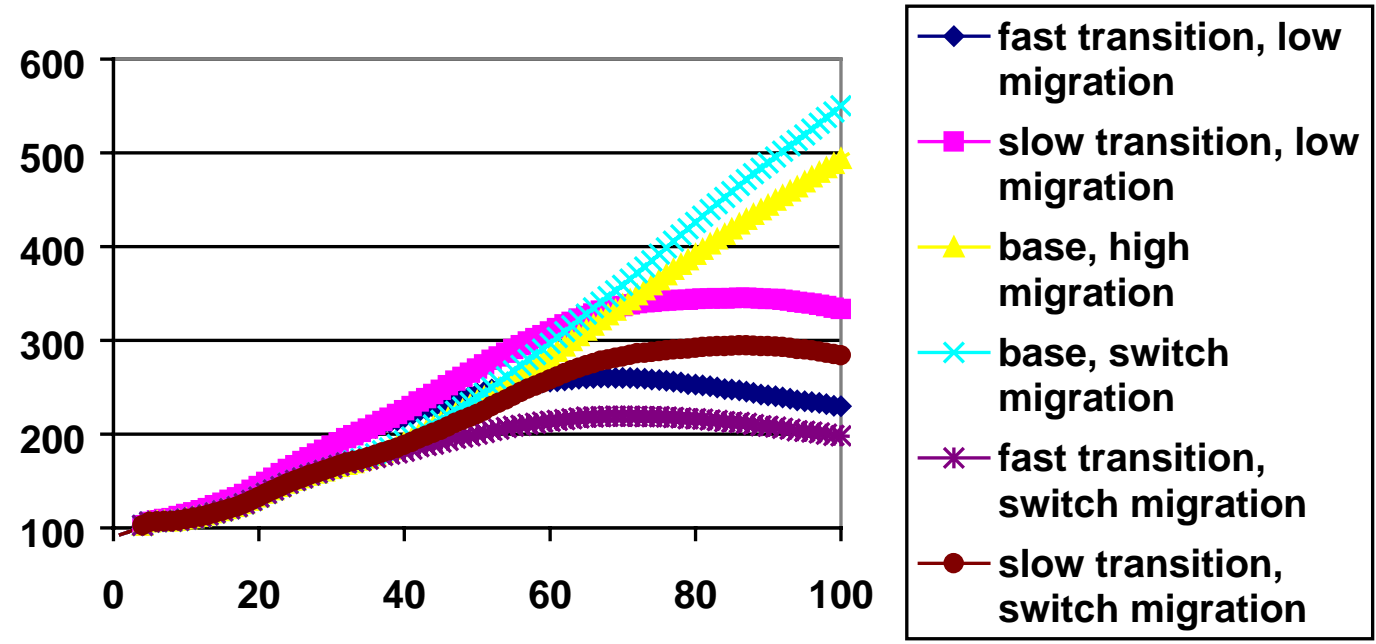

Figure 5. Average size of the workforce (population aged 18-65) for Poor2 under six distinct population reduction strategies. The runs differ in the speed of the fertility transition or decline (as described in the text) and in the out-migration policy. The "high" and "switch" policies are the same for the first 50 periods, while the "low" and "switch" are the same for the second 50 periods. "Base" refers to a run with no fertility policy. The policies are described in more detail on page 23 of the text. 


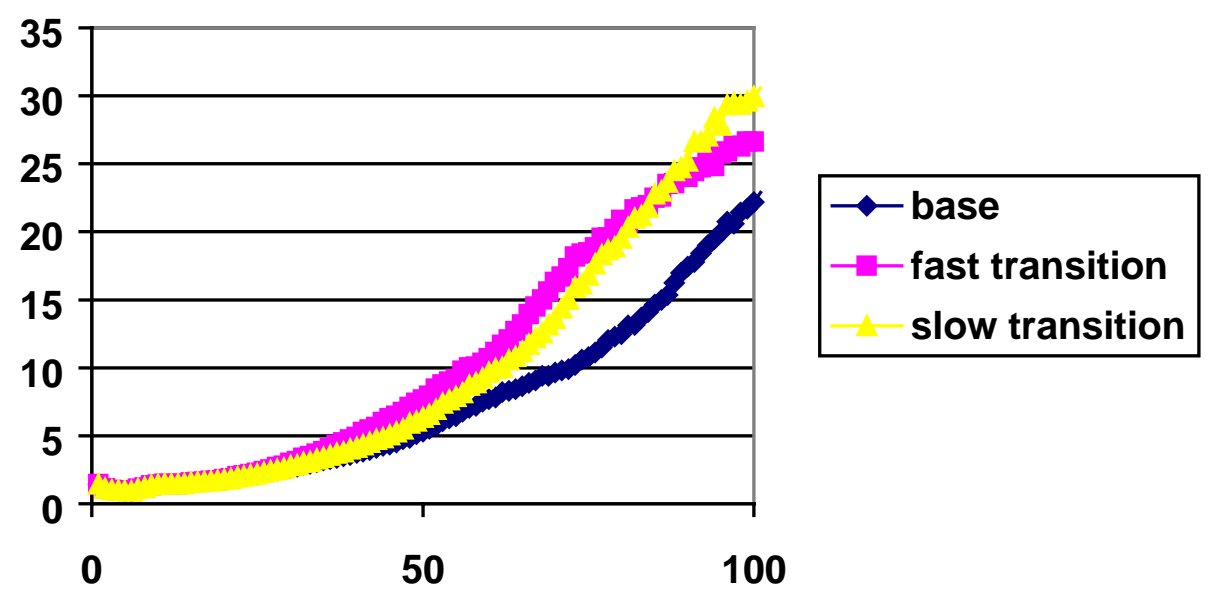

Figure 6. Average per capita GDP for Poor2 under three different fertility transitions: "base" refers to fertility control (c) as described on page 23 in the text; "fast transition" to fertility control (a); and "slow transition" to fertility control (b). Results are qualitatively the same for Poor1.
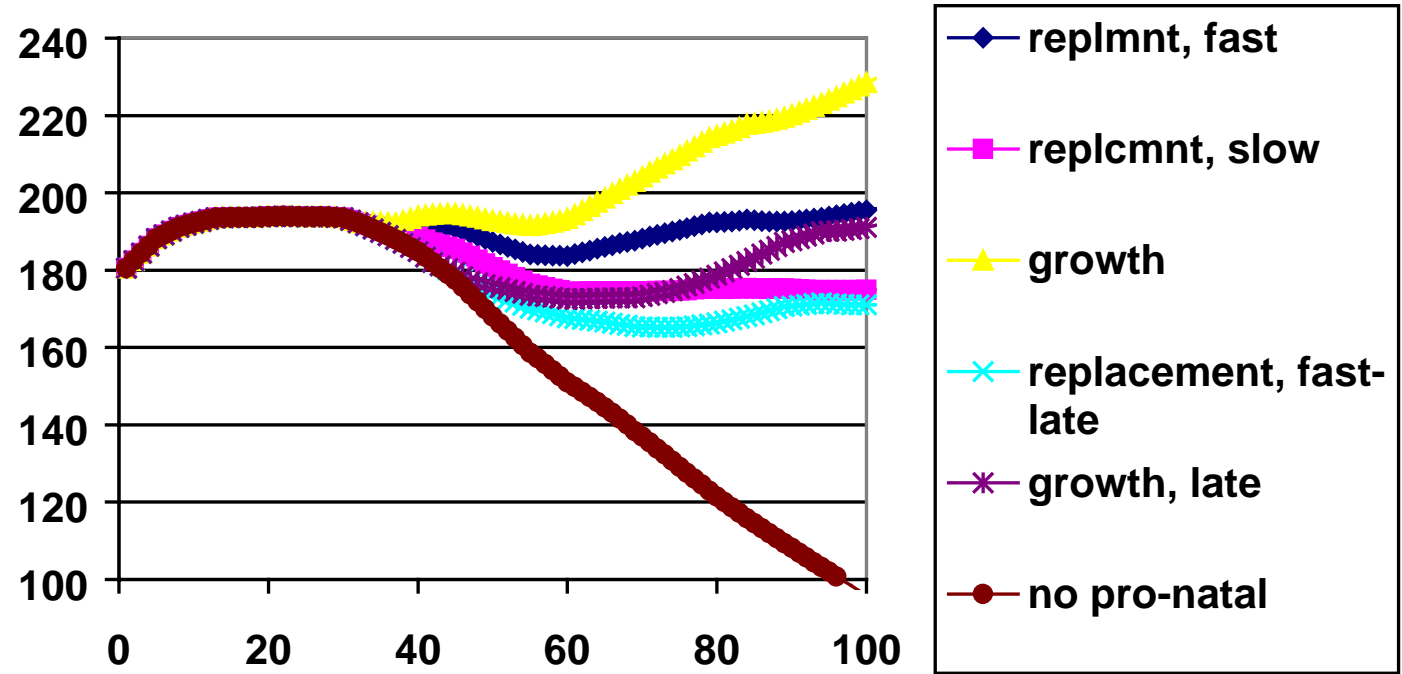

Figure 7 (a) The size of workforce for Rich2 under pro-natal polices that do not include migration. The changes in fertility that correspond to the three policies, "replacement, fast," "replacement, slow," and "growth" are defined in the text. The distinction "late" means the policy takes effect in period 20 rather than period 10 . The default or base case of no policy is "no pronatal." 


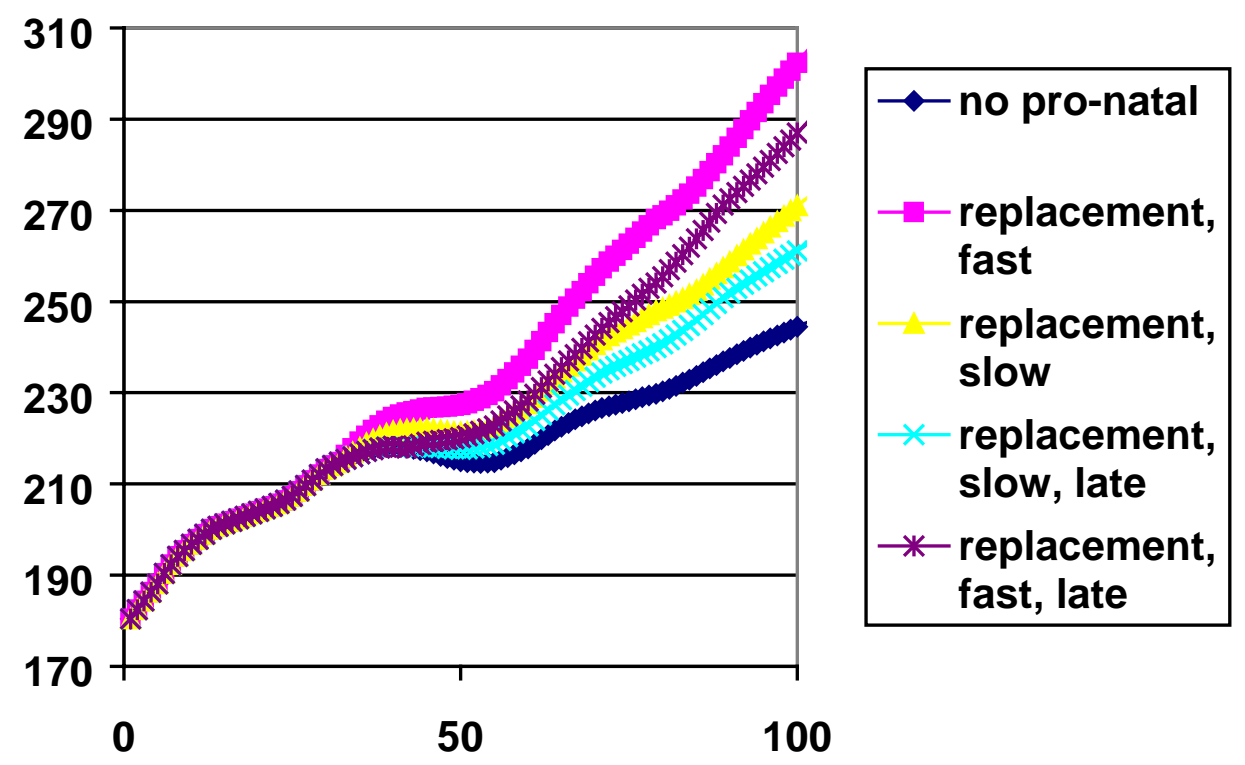

Figure 7 (b). The size of workforce for Rich2 under pro-natal polices that include migration. The changes in fertility that correspond to the two policies, "replacement, fast" and "replacement, slow" are defined in the text. The distinction "late" means the policy takes effect in period 20 rather than period 10. The default or base case of no policy is "no pro-natal"; this run, however, does include migration. 